\title{
Fisiopatologia da deficiência de vitamina B12 e seu diagnóstico laboratorial
}

\author{
Physiopathology of vitamin B12 deficiency and its laboratorial diagnosis
}

Clóvis Paniz'1, 2; Denise Grotto²; Gabriela Cristina Schmitt'; Juliana Valentini²; Karen Lílian Schott ${ }^{2}$; Valdeci Juarez Pomblum ${ }^{3}$; Solange Cristina Garcia ${ }^{4}$

\begin{abstract}
unitermos
Vitamina B12

Diagnóstico

Soro

Transcobalaminas

Hiper-homocisteinemia

Ácido metilmalônico

\section{resumo}

Introdução: A vitamina B12 é hidrossolúvel, não-sintetizada pelo organismo humano, presente em alimentos de origem animal. Sua deficiência é muito freqüente entre idosos, vegetarianos e indivíduos que adotam baixa dieta protéica ou apresentam problemas de absorção gastrintestinal. Fisiopatologia: A deficiência de vitamina B12 leva a transtornos hematológicos, neurológicos e cardiovasculares, principalmente, por interferir no metabolismo da homocisteína (Hcy) e nas reações de metilação do organismo. Muitas vezes a deficiência pode permanecer assintomática por longos períodos, desencadeando uma deficiência crônica que, se mantida, pode levar a manifestações neurológicas irreversíveis. Metodologias: Metodologias eficientes que permitam um diagnóstico precoce são imprescindíveis. Porém um método considerado padrão-ouro ainda não é consensual. A dosagem sérica de vitamina B12 sofre algumas restrições pelos problemas de sensibilidade e especificidade, podendo ocorrer sintomas de deficiência mesmo com vitamina B12 sérica dentro dos níveis normais ou, de outro modo, ocorrendo baixos níveis de vitamina B12 sérica sem, contudo, apresentar baixos níveis da fração de vitamina realmente disponível para as células e sem apresentar sintomatologia. Novas alternativas vêm surgindo, como a dosagem de transcobalamina II (Tc II), a única fração de vitamina B12 disponível para as células, ou a dosagem de ácido metilmalônico (MMA) e Hcy, metabólitos que aumentam quando ocorre diminuição de vitamina B12 intracelular. Estes testes apresentam algumas vantagens, mas também limitações importantes para uso rotineiro. Conclusão: Em casos subclínicos, um diagnóstico correto e precoce representa ainda um desafio, e futuros estudos são necessários para definir um método padrão para diagnóstico laboratorial da deficiência de vitamina B12.
\end{abstract}

Introduction: The vitamin B12 is a water soluble vitamin, not synthetized by humans organisms, found in foods of animal origin. Its deficiency is very frequent among old people, vegetarians, subjects who use a low protein diet, or who present gastrointestinal absorption failure. Physiopathology: The vitamin B12 deficiency leads to hematologic, neurophatologic and cardiovascular disorders, mainly by interfering in the homocysteine (Hcy) metabolism and in the methylation reactions of organism. Often, the deficiency can remain without symptoms for long time, leading to a chronic deficiency that, if not treated, may yield irreversible neurologic manifestations. Methodology: Efficient methodologies that allow the early diagnosis are essential. However, a gold standard method is not consensus yet. The vitamin B12 serum measurement presents some restrictions for problems of sensitivity and specificity, being able to occur deficiency's symptoms even the serum vitamin B12 being in normal range or, in another way, occurring low levels of serum vitamin B12 without, however, showing low levels of vitamin B12 fraction really available for the cells and without showing symptoms. New alternatives come appearing, as the transcobalamin II measurement, the only vitamin B12 fraction available for the cells or the methylmalonic acid and Hcy measurement, metabolites that increase when intracellular vitamin B12 decreases. These tests present some advantages, but also important limitations for use in the routine. Conclusion: In the sub clinical cases, a correct and early diagnosis represents still a challenge and further studies are needed to define the best method for routine laboratorial diagnosis of vitamin B12 deficiency.

\section{key words}

Vitamin B12

Diagnosis

Serum

Transcobalamins

Hyperhomocysteinemie

Methylmalonic acid

\footnotetext{
1. Farmacêutico-bioquímico do Laboratório de Análises Clínicas do Hospital Universitário de Santa Maria da Universidade Federal de Santa Maria (HUSM/UFSM).

2. Farmacêutico-bioquímico do Laboratório de Toxicologia (LATOX) do Departamento de Análises Clínicas e Toxicológicas da UFSM.

3. Médico doutor em Medicina do Departamento de Clínica Médica da UFSM.

4. Professora doutora em Farmácia-Bioquímica do Departamento de Análises Clínicas e Toxicológicas da UFSM.
} 


\section{Introdução}

A vitamina B12, ou cianocobalamina, faz parte de uma família de compostos denominados genericamente de cobalaminas $^{(105)}$. É uma vitamina hidrossolúvel, sintetizada exclusivamente por microrganismos ${ }^{(38)}$, encontrada em praticamente todos os tecidos animais e estocada primariamente no fígado na forma de adenosilcobalamina ${ }^{(41)}$. A fonte natural de vitamina $B 12$ na dieta humana restringe-se a alimentos de origem animal ${ }^{(38,42,46,47,64)}$, especialmente leite, carne e ovos ${ }^{(32,64)}$.

Em países industrializados, estudos epidemiológicos mostraram uma prevalência da deficiência de vitamina B12 na população geral próxima a $20 \%$ (5\%-60\% conforme a definição de deficiência de vitamina usada no estudo). Em países em desenvolvimento como Índia, México e Guatemala, foi verificada alta deficiência de vitamina B12 em gestantes, lactantes e crianças em período de amamentação ${ }^{(68)}$. Além disso, estudos com crianças maiores, não-lactentes, no México e na Venezuela demonstraram que 33\%-52\% dos indivíduos deste grupo apresentavam baixos níveis plasmáticos de vitamina B12 ${ }^{(2,29)}$.

A deficiência dessa vitamina pode ocasionar transtornos hematológicos, neurológicos e cardiovasculares( ${ }^{(6)}$, estando ela diretamente relacionada com a hiper-homocisteinemia $(\mathrm{HHcy})^{(100)}$, um fator independente de risco cardiovascu$\operatorname{lar}^{(14,16,19,23,45,47,55)}$ e de danos neuroniais ${ }^{(19,36)}$. Dessa forma, o diagnóstico precoce da deficiência de vitamina B12 é de grande importância para evitar danos patológicos irreversíveis. Entretanto inexiste uma metodologia laboratorial considerada adequada ${ }^{(20,52,69,78)}$, já que as possibilidades metodológicas disponíveis apresentam, entre outras coisas, problemas de sensibilidade e especificidade ${ }^{(45,52,55,60,69,79)}$.

Devido a esses aspectos, essa deficiência deve ser considerada um importante problema de saúde pública, principalmente entre pessoas idosas e indivíduos que adotam uma dieta estritamente vegetariana (vegans) ${ }^{(19,70,99)}$.

\section{Histórico}

No início de 1920, Minot e Murphy demonstraram poder curar a anemia perniciosa, uma doença anteriormente incurável, adotando uma dieta à base de fígado ${ }^{(47)}$, o que aumentou em mais que o dobro a contagem de células vermelhas dos pacientes em um mês ${ }^{(80)}$. Em 1945, um princípio ativo, efetivo como antianêmico, foi concentrado a partir de tecido hepático. Lester Smith e Folkers, em 1947, cristalizaram o princípio ativo do extrato hepático envolvido na regressão da anemia e o denominaram de vitamina B12, descrevendo-o como um composto cianídrico contendo um átomo de cobalto ${ }^{(80)}$.

\section{Química}

A vitamina B12 tem um peso molecular de $1,355 \mathrm{kDa}$. O termo vitamina B12 é atribuído a uma família de substâncias compostas por um anel tetrapirrólico que circunda um átomo central de cobalto, um grupo nucleotídico, que consiste na base 5,6-dimetilbenzimidazol e numa ribose fosforilada esterificada com 1-amino, 2-propanol(32, 41,55) (Figura 1). O nome do grupo é cobalamina, e ele pode apresentar diferentes ligantes, cada um conferindo um nome diferente: metil (metilcobalamina), hidroxil (hidrocobalamina), água (aquacobalamina), cianeto (cianocobalamina) e S-deoxiadenosina (deoxiadenosilcobalamina). Quimicamente, o termo vitamina B12 refere-se a hidroxicobalamina ou cianocobalamina, ainda que genericamente seja aplicado para todas as formas de cobalamina. A forma predominante no soro é a metilcobalamina, e no citosol, a adenosilcobalamina ${ }^{(32,55)}$. Muitos ensaios de vitamina B12 medem todas essas formas após conversão em cianocobalamina ${ }^{(55)}$, a qual é a forma manufaturada pela indústria ${ }^{(47)}$.

A vitamina B12, quando em solução, é termoestável, mas sofre decomposição pela ação da luz e dos álcalis ${ }^{(90)}$.

\section{Absorção}

A vitamina B12 é liberada pela digestão de proteínas de origem animal, sendo então capturada pela haptocorrina (também denominada transcobalamina I [TC I] ou holo- $\mathrm{Hc})^{(1,38,46)}$, uma proteína $\mathrm{R}$ produzida na saliva e no estômago ${ }^{(47)}$, sendo esse complexo posteriormente degradado pelas proteases pancreáticas com conseqüente transferência da molécula de vitamina B12 para um fator intrínseco gástrico (FI), uma glicoproteína de 44kDa produzida pelas células parietais do estômago. A ligação da vitamina $\mathrm{B} 12$ ao $\mathrm{Fl}$ forma na mucosa um complexo que deve resistir às enzimas proteolíticas da luz intestinal ${ }^{(1,64)} \mathrm{e}$ que, posteriormente, adere-se a receptores específicos das células epiteliais do íleo terminal, onde a vitamina B12 é absorvida e ligada a um transportador plasmático e lançada na circulação(1). Várias horas são necessárias para a sua absorção. O FI não é absorvido pelo intestino, sendo expelido sem transformação( $26,38,105)$. A vitamina B12, absorvida no íleo terminal, é então ligada à Tc II, adentra a circulação portal e é distribuída para as células que expressam receptores 


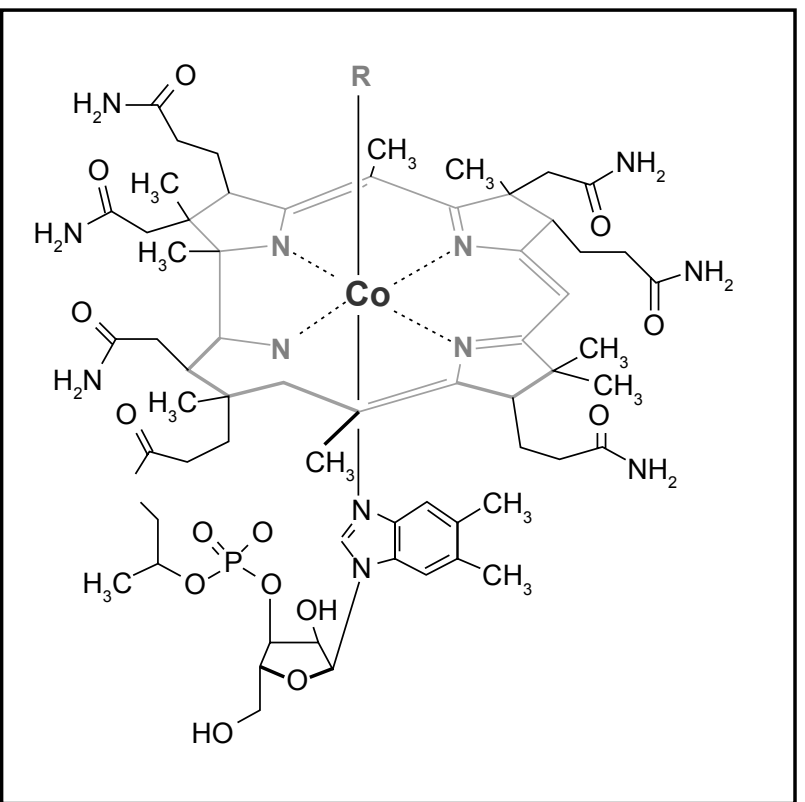

Figura 1 - Estrutura da vitamina B12

específicos, os quais internalizam a vitamina na forma de complexo Tc-vitamina B12(99).

Qualquer alteração no processo da absorção leva à deficiência de vitamina B12 ${ }^{(105)}$. Na ausência de Fl, a absorção da vitamina B12 é prejudicada e, finalmente, segue-se a deficiência de vitamina. Numa deficiência relativamente comum que ocorre mais em adultos, a falta de $\mathrm{Fl}$ está associada à atrofia gástrica e à deficiência de muitas outras secreções gástricas. Ocorre ainda uma forma de deficiência congênita onde falta apenas o fator intrínseco ${ }^{(41)}$. Ambas vão se traduzir em deficiência da vitamina e caracterizarão uma patologia denominada anemia perniciosa, na qual podem ser encontrados anticorpos anti-Fl e anticélulas parietais $^{(58)}$.

\section{Transportadores plasmáticos}

No plasma, a vitamina B12 circula ligada às proteínas transportadoras denominadas transcobalaminas, que são três. A maior parte da vitamina B12 circula ligada à holo$\mathrm{Hc}^{(20,38,62)}$. Uma outra porção é transportada pela holo-Tc, que representa aproximadamente $10 \%$ a $30 \%$ da fração circulante de vitamina $B 12^{(31,38,62,99)}$, e uma pequena fração de vitamina B12 circula ligada à transcobalamina III (TC III) $)^{(41)}$.

A holo-Hc é uma glicoproteína de transporte ${ }^{(11)}$ de, aproximadamente, $120 \mathrm{kDa}^{(4)}$, e, embora represente a maior fração de vitamina B12 circulante, é considerada inerte porque não existem receptores celulares para holo-Hc nas células ${ }^{(20)}$ e por sua função no organismo ser pouco conhecida ${ }^{(11,99)}$.
A holo-Hc é liberada no plasma pelos granulócitos, podendo ocorrer reduções de holo-Hc circulante por decréscimo da massa total de granulócitos ${ }^{(32,41)}$. O aumento da massa de granulócitos na policitemia vera pode ser responsável por uma liberação maior de holo-Hc, elevando os níveis séricos de vitamina $B 12^{(105)}$ e podendo mascarar uma possível deficiência, já que o aumento desta fração não representa maior disponibilidade de vitamina B12 por parte das células. Dessa forma, a holo-Hc assume importância clínica, pois sua elevação produzirá falsos aumentos de vitamina B12 ${ }^{(55)}$. De outro modo, diminuições de holo-Hc podem levar a níveis falsamente mais baixos de vitamina B12 sérica total, não representando deficiência real, pois esta fração não está disponível para utilização pelas células. Segundo Carmel ${ }^{(19)}$, $15 \%$ das baixas concentrações de vitamina B12 não-explicados foram associadas com baixa concentração de holoHc. Esses resultados indicam que a deficiência de holo-Hc poderia estar associada às causas comuns de baixa vitamina $B 12^{(21)}$. A deficiência de holo-Hc não leva às manifestações características da deficiência de vitamina B12 ${ }^{(41)}$.

A holo-Tc, uma proteína de $43 \mathrm{kDa}^{(84)}$, é produzida por fígado, macrófagos e íleo ${ }^{(105)}$, e contém a fração biologicamente ativa da cobalamina, pois promove a entrada específica da cobalamina em todas as células do corpo $^{(20,42,46,62,63,74,78)}$. A holo-Tc plasmática encontra-se em um estado dinâmico e pode diminuir devido a problemas de má absorção, depleção das reservas, danos hepático e renal( $^{(63)}$ e por deficiência congênita ${ }^{(26)}$. A falta de holo-Tc resulta em anemia megaloblástica severa na infância, mas os níveis séricos de vitamina B12 poderão estar normais devido a valores mais elevados de holo- $\mathrm{Hc}^{(41)}$.

Por representar a única fração acessível às células, surgiu interesse na possível dosagem da holo-Tc, preferencialmente quanto às dosagens de vitamina B12 total no soro/ plasma $^{(20,62,85)}$ como um marcador precoce de deficiência tecidual desta vitamina ${ }^{(63)}$ e um melhor indicador do balanço negativo de níveis de vitamina B12 intracelular ${ }^{(1)}$.

A Tc III é, provavelmente, uma isoproteína da holo-Hc, não-saturada com cobalamina e, portanto, menos carregada. É liberada pelos granulócitos durante a coagulação in vitro e produzida por várias células como fibroblastos, macrófagos, enterócitos, células renais, hepatócitos, mucosa gástrica e endotélio ${ }^{(41)}$. A Tc III não foi ainda estudada quanto à sua função. Talvez atue como um lixeiro de metabólitos inúteis e potencialmente perigosos análogos da vitamina B12 que circulam pelo sangue. Alguns estudos sugerem que a Tc III transporta B12 rápida e exclusivamente para o fígado(8). 


\section{Funções metabólicas}

A vitamina B12 é essencial em diversas reações bioquímicas na natureza, a maioria das quais implica redistribuição de hidrogênios e de carbonos ${ }^{(10)}$. No organismo humano funciona como um co-fator essencial para duas enzimas: metionina sintase e L-metilmalonil-coA mutase ${ }^{(10,45,70,77,91,95)}$, ambas direta ou indiretamente envolvidas no metabolismo da homocisteína (Hcy) (Figura 2).

A metionina sintetase promove a metilação da Hcy à metionina, tendo o 5-metiltetraidrofolato (5-MTHF) como doador de grupamento metil e a metilcobalamina como co-fator ${ }^{(24,49,68,77,100)}$. Após a metilação da Hcy, a metionina formada é condensada com o trifosfato de adenosina (ATP), resultando na S-adenosilmetionina (SAM). Em seguida, por uma reação de desmetilação, forma-se a S-adenosil-homocisteína (SAH) com posterior hidrólise para liberar adenosina e Hcy, completando o ciclo(25).

A metilação da Hcy serve para repor os estoques de SAM quando a metionina dietética estiver em baixos níveis. A SAM é o único doador de grupamentos metil para numerosas reações de metilação, incluindo algumas essenciais para a manutenção da mielina ${ }^{(10)}$. Assim, além do aumento de $\mathrm{Hcy}$, a deficiência de vitamina B12 causará diminuição da SAM e conseqüente redução de importantes reações de transmetilação do organismo ${ }^{(69)}$, provocando defeitos desmielinizantes no sistema nervoso $0^{(9,13)}$.
Outro problema conseqüente à interrupção da conversão de Hcy em metionina é que o 5-MTHF, doador de grupamentos metil na reação, não pode ser convertido em tetraidrofolato (THF) eficientemente, ocasionando um seqüestro de folatos na forma 5-MTHF, ocorrendo, assim, deficiências de outros metabólitos dos folatos, como o 5,10metilenotetraidrofolato, co-fator fundamental na síntese do ácido desoxirribonucléico $(\mathrm{DNA})^{(10)}$. Desse modo, gerará um defeito na síntese de DNA, dificultando a divisão celular na medula, enquanto que o ácido ribonucléico (RNA) e a síntese de componentes celulares permanecem inalterados, produzindo macrocitose ${ }^{(91)}$. Portanto, a interrupção da síntese de DNA na deficiência de vitamina B12 é secundária ao transtorno no metabolismo dos folatos ${ }^{(10)}$.

Quando há deficiência de vitamina B12, a reação de metilação ou remetilação da Hcy fica prejudicada e a via de transulfuração representa a alternativa metabólica para a Hcy nos casos em que os níveis de metionina, por quaisquer motivos, estejam elevados. Nesse caminho, a Hcy combina-se com a serina para formar cistationina, em reação catalisada pela cistationina- $\beta$-sintase ${ }^{(35)}$. Em uma reação subseqüente, a cistationina é hidrolisada para formar cisteína e $\alpha$-cetobutirato ${ }^{(50)}$, ambas reações dependentes de vitamina $B 6^{(33)}$ (Figura 2, etapa 4). Assim, altas concentrações de SAM estimulam a enzima cistationina- $\beta$-sintase, facilitando a eliminação do excesso de Hcy e, conseqüentemente, de metionina ${ }^{(50)}$.

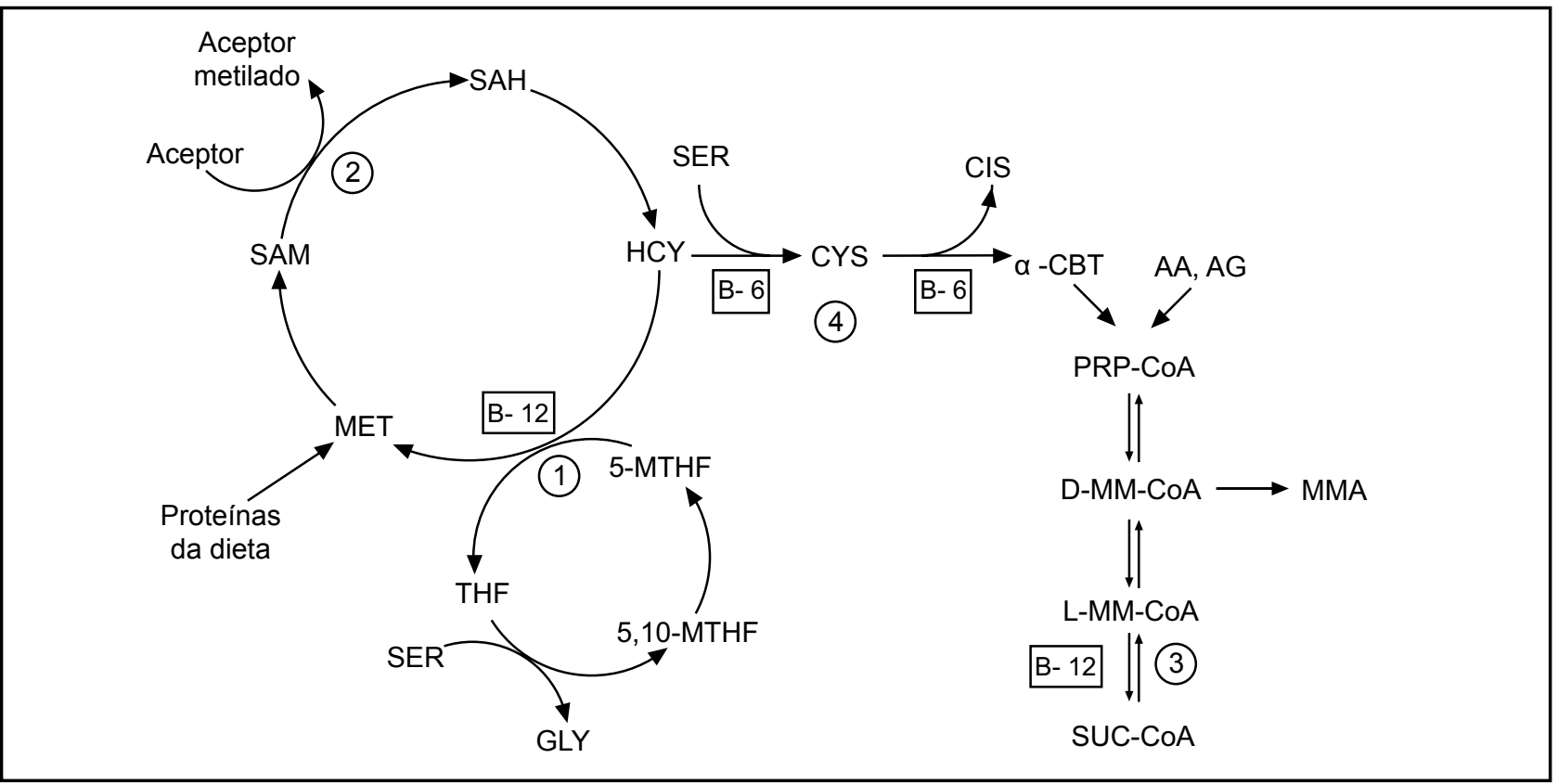

Figura 2 - Reações envolvendo a vitamina B12 e síntese de Hcy e MMA. 1. Reação de metilação da homocisteína (metionina sintase); 2. doação de grupamentos metil; 3. reação de isomerização do metilmalonil-coA para succinil-coA (L-metil malonil-CoA mutase); 4. reações da via de transulfuração dependentes de vitamina B6 (cistationina-Bsintase e cistationina---liase). SAM, S-adenosil metionina; SAH, S-adenosil homocisteína; CYS, cistationina; CIS, cisteína; $\alpha$-CBT, $\alpha$-cetobutirato; PRP-COA, propionil-CoA; THF, tetrahidrofolato; 5-MTHF, 5-metiltetrahidrofolato; 5,10-MTHF, 5,10 metileno tetrahidrofolato; AA, aminoácidos; AG, ácidos graxos [Herrmann et al., 2003 modificado] ${ }^{\text {(45) }}$ 
Nesta rota de eliminação do excesso de Hcy é que aparece a segunda enzima dependente de vitamina B12, a L-metilmalonil-coA mutase, que faz a conversão de metilmalonil coenzima A para succinil coenzima $A$, tendo a adenosilcobalamina como co-fator ${ }^{(10,45,70,77,91,95)}$ (Figura 2, etapa 3). Esta reação é de grande importância na reutilização mitocondrial do propionil-coA, inclusive daquele procedente da conversão do $\alpha$-cetobutirato proveniente da via de transulfuração da Hcy, para a obtenção de energia através da formação de ATP no ciclo de Krebs ${ }^{(10)}$, ou envolvimento na síntese de porfirinas ${ }^{(45,69)}$.

A deficiência de vitamina B12 impede esta reação desviando o substrato para a formação de ácido metilmalônico (MMA) ${ }^{(55)}$. Conseqüentemente, levará a aumentos de MMA sangüíneo e urinário ${ }^{(10,55,69)}$ e também a elevações de ácido propiônico, produzindo acidose metabólica ${ }^{(10)}$. Uma redução completa do fluxo através da reação da metilmalonil-coA mutase é discutida por sua contribuição nos conseqüentes danos neurológicos associados à deficiência de vitamina B12 ${ }^{(47)}$.

Além das deficiências de vitaminas B12, outros fatores podem levar à HHcy, como deficiência de folatos e de vitamina B6, defeitos genéticos que afetam o funcionamento de algumas enzimas envolvidas nestes processos, insuficiência renal crônica e alguns fármacos, como o metotrexato $^{(17,55)}$.

\section{Manifestações clinicolaboratoriais}

A deficiência assintomática de vitamina B12 pode ocorrer por longos períodos antes do aparecimento de qualquer sinal ou sintoma clínico ${ }^{(20,56)}$, desencadeando uma deficiência crônica de vitamina B12 que, se mantida durante anos, pode levar a manifestações neuropsiquiátricas irreversíveis ${ }^{(6)}$.

As manifestações clínicas da deficiência de vitamina B12 são polimórficas, variando de estados mais brandos até condições muito severas ${ }^{(6)}$. De uma maneira geral, é uma desordem que se manifesta por um quadro clássico caracterizado por anemia megaloblástica associada a sintomas neurológicos ${ }^{(6,19,47,85)}$ com freqüente aparecimento da tríade fraqueza, glossite e parestesias ${ }^{(58,105)}$. Porém, danos neurológicos podem ocorrer mesmo na ausência de anemia numa parcela considerável de pacientes ${ }^{(52,99)}$.

As alterações hematológicas típicas da deficiência de vitamina B12 são caracterizadas por diminuição de hemoglobina, caracterizando anemia, que tem como um dos principais aspectos a presença de macroovalócitos, neutrófilos hiper-segmentados ${ }^{(85,93)}$ e hipercelularidade na medula óssea com maturação anormal(3), representando uma anemia megaloblástica. Podem-se observar também baixas contagens plaquetárias ${ }^{(3,85)}$.

As manifestações neurológicas devem-se a danos progressivos dos sistemas nervosos central e periférico( ${ }^{(99)}$, e tipicamente manifestam-se com polineurites, principalmente sensoriais, nas extremidades distais, ataxia e reflexo de Babinski( ${ }^{(6)}$. Além disso, são comuns relatos de déficits de memória, disfunções cognitivas, demência ${ }^{(19,41,88)}$ e transtornos depressivos ${ }^{(82,96)}$.

Nos últimos anos, estudos têm reconhecido a importância da deficiência de vitamina B12 no desenvolvimento de danos neurológicos em crianças ${ }^{(39)}$. As manifestações clínicas em crianças tornam-se particularmente relevantes quando a deficiência de vitamina B12 ocorre desde o nascimento, e os danos são freqüentemente mais acentuados do que aqueles que ocorrem em crianças maiores ou adultos ${ }^{(34)}$.

A deficiência de vitamina B12 em gestantes aumenta o risco de malformação fetal, ocasionando defeito no tubo neural e constituindo-se numa das mais comuns alterações congênitas ${ }^{(1,54)}$.

Além dessas alterações, a sua deficiência contribui para a HHcy, um fator de risco independente para aterosclero$\mathrm{se}^{(14,16,19,23,45,47,55)}$ devido a sua associação com o aumento da geração de espécies reativas de oxigênio, da peroxidação lipídica e do dano tecidual do endotélio vascular $\left.{ }^{(59,}, 92,02\right)$, aumentando o risco de doenças cérebro e cardiovascula-

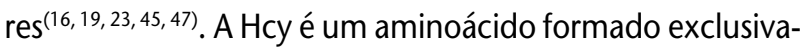
mente a partir da desmetilação da metionina proveniente da dieta ou de seu catabolismo(71), sendo sua elevação plasmática associada com doença vascular prematura em adultos ${ }^{(100)}$, proposta como a explicação metabólica para a freqüente coexistência de HHcy e dano vascular e degenerativo no cérebro ${ }^{(36,75)}$ e considerada um fator de risco para demência ${ }^{(47)}$ e transtornos depressivos ${ }^{(27)}$. Estudos in vitro $\mathrm{e}$ em animais sugerem que a HHcy não apenas lesa o endotélio vascular, levando à aterosclerose e ao tromboembolismo ${ }^{(103)}$, mas também promove a síntese de várias citocinas pró-inflamatórias na parede arterial ${ }^{(28,51,83)}$. A concentração de Hcy plasmática normalmente encontra-se entre $8 \mathrm{e}$ $12 \mu \mathrm{M}$. Contudo pequenas elevações $(\sim 5 \mu \mathrm{M})$ no plasma aumentam em $60 \%$ os riscos de doença arterial coronariana (DAC) para homens e até $80 \%$ para mulheres ${ }^{(15)}$.

A identificação da deficiência de vitamina B12 é importante devido ao inapropriado tratamento com ácido fólico, que corrige os sinais hematológicos, mascarando a 
deficiência dessa vitamina, propiciando o desenvolvimento de sintomas neurológicos ${ }^{(19,24)}$ através de provável aceleração da desmielinização neuronial ${ }^{(9,13,70)}$ e permitindo progressivos e irreversíveis danos neurológicos ${ }^{(19)}$.

Pela gravidade que esta deficiência representa e pela variedade de patologias associadas, faz-se necessário um precoce e correto diagnóstico laboratorial a fim de que se previnam muitos dos transtornos que poderiam ser produzidos ou desencadeados pela ausência de vitamina B12, muitos deles irreversíveis ${ }^{(47)}$.

\section{Diagnóstico da deficiência e metodologias disponíveis}

Nos últimos anos, busca-se desenvolver testes mais eficientes para diagnosticar a deficiência de vitamina B12, pois marcadores que representem melhor as concentrações intracelulares dessa vitamina acrescentam maior confiança aos resultados, permitindo um diagnóstico precoce e uma avaliação em pacientes assintomáticos ou aparentemente saudáveis, os quais poderiam estar desenvolvendo importante insuficiência funcional desta vitamina ${ }^{(19,22,47)}$. $\mathrm{O}$ conceito de deficiência de vitamina B12 foi expandido além da anemia megaloblástica, passando-se a levar em consideração também os danos neurológicos ${ }^{(18)}$. Isto se tornou possível com o aumento de sensibilidade dos testes usados até então e pela introdução de novos marcadores da deficiência de vitamina B12, como dosagem de transportadores (holo-Tc) ${ }^{(44,63,97)}$, e de metabólitos, como o MMA e a Hcy, que se elevam com a diminuição da disponibilidade de vitamina $\mathrm{B} 12^{(6,18,19)}$.

Desse modo, o diagnóstico da deficiência de vitamina B12, que era embasado na presença de sintomatologia clínica e/ou anemia macrocítica associada a níveis baixos de vitamina B1 2 sérica, passou a desempenhar um papel mais amplo $^{(18,20,22,52,69)}$, principalmente pela atenção dada a pacientes assintomáticos. Nesses pacientes tem-se percebido que deficiências significativas de vitamina B12 detectadas por aumentos de MMA e Hcy podem ocorrer com certa freqüência, mesmo na ausência de danos hematológicos e sem a necessidade de baixos níveis de vitamina $B 12$ sérica total|(22). A associação desses testes laboratoriais tem auxiliado a reconhecer e estudar estágios precoces, expandindo a definição de deficiência de vitamina B12(18).

Os testes para diagnosticar deficiência de vitamina B12 variam largamente no que diz respeito à sensibilidade e à especificidade ${ }^{(91)}$. Dessa forma, muitas dificuldades diagnósticas laboratoriais têm sido encontradas e ainda não se estabeleceu um consenso para um teste que fosse considerado padrão-ouro para o diagnóstico dessa deficiência ${ }^{(6,20,52,63,78,91)}$. Entre os exames laboratoriais existem os de rotina, como a vitamina B12 e Hcy séricas, e aqueles mais destinados à pesquisa e/ou mais restritos a laboratórios especializados, como a dosagem de holo-Tc e MMA.

\section{Vitamina B12 sérica}

Os níveis de vitamina $\mathrm{B} 12$ séricos são considerados baixos quando sua concentração é inferior a $200 \mathrm{pg} / \mathrm{ml}$ $(148 \mathrm{pmol} / \mathrm{I})^{(19,69,91)}$. A medida de vitamina B12 sérica é o teste mais comumente utilizado para diagnosticar deficiên-

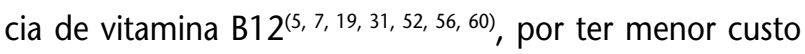
e ser mais conhecida ${ }^{(19)}$. Porém, a dosagem de vitamina B12 sérica apresenta limitações de sensibilidade e muitas controvérsias sobre sua especificidade $(5,19,45,52,56,60,69,79)$. Além disso, sofre influência direta das concentrações de proteínas ligantes (transcobalaminas), sendo, deste modo, um indicador pobre dos níveis de vitamina B12 realmente disponíveis para a célula(52). Falsos aumentos são causados por desordens mieloproliferativas, e valores falsamente diminuídos podem ser encontrados na deficiência de folatos, na gravidez e em deficiências de $\mathrm{Tc}^{(5,22)}$.

Segundo Lindenbaum et al.(60), os níveis séricos de vitamina B12 encontram-se normais numa significativa minoria de pacientes com deficiência desta vitamina e, ainda, segundo esses autores, a medida de alguns metabólitos da vitamina, como MMA e Hcy no soro, facilitaria a identificação da deficiência nesses indivíduos ${ }^{(6)}$.

Carmel et al.(19) preconizam que, quando presentes os sintomas clínicos da deficiência, em $97 \%$ dos casos os níveis de vitamina B12 estão abaixo dos valores de referência ( $<200 \mathrm{ng} / \mathrm{l} ;<148 \mathrm{pmol} / \mathrm{l})$, demonstrando que este teste ainda encontra utilidade quando aplicado a pacientes sintomáticos ${ }^{(19)}$.

Mesmo que apresente limitações de especificida$\mathrm{de}^{(19,22,47)}$ e sensibilidade, nenhum outro substituto para esta metodologia é ainda universalmente aceito ${ }^{(7,19)}$. Estudos recentes utilizando os metabólitos MMA e Hcy confirmaram que baixas concentrações de vitamina B12 em pacientes assintomáticos ou aparentemente saudáveis representavam uma relevante insuficiência funcional dessa vitamina, e não um resultado falsamente diminuído como se pensava ${ }^{(18,47)}$. Além disso, a correção de diversos problemas técnicos com os radioensaios utilizados, a melhor definição do intervalo de referência e a introdução de ensaios mais sensíveis e específicos utilizando imunoensaios, entre outros, têm 
conferido maior confiabilidade para detectar deficiências de vitamina B12 em pacientes sintomáticos ${ }^{(93)}$, embora não exista método de consenso para dosagem de vitamina B12 por apresentarem, os existentes, grandes variações de desempenho entre si ${ }^{(91)}$. Alguns dos métodos mais utilizados incluem ensaios microbiológicos e radioisotópico ${ }^{(57,89)}$, cinéticos ${ }^{(89)} \mathrm{e}$, mais recentemente, imunoensaios por quimioluminescência ${ }^{(23,53,78)}$, radioimunoensaios ${ }^{(52,57,70,81)}$, ensaios imunoenzimáticos ${ }^{(43,94,98)}$, imunoensaios fluorimétricos ${ }^{(48)}$, entre outros.

\section{Holo-Tc}

A holo-Tc, fração biologicamente ativa da vitamina $B 12^{(20,62,85,101)}$, passou a ter importância em metodologias que permitissem a sua dosagem, viabilizando um marcador precoce de deficiência tecidual de vitamina B12, uma vez que esta se encontra diminuída antes do aparecimento de sinais e sintomas clínicos ${ }^{(44,63)}$ e que seria um melhor indicador do balanço negativo de níveis de vitamina B12 plasmática ${ }^{(1)}$. Tisman et al. ${ }^{(97)}$ sugerem que a medida dos níveis de holo-Tc poderia refletir melhor a disponibilidade celular de vitamina B12 do que a dosagem dos níveis de vitamina $B 12$ sérica ${ }^{(97)}$.

A Tc insaturada, ou seja, aquela não ligada com vitamina B12, pode ser medida por cobalamina marcada, mas medidas de Tc total ou de Tc com vitamina B12 são mais complicadas ${ }^{(86)}$.

O principal problema para a utilização da holo-Tc como marcador de deficiência de vitamina B12, entre outros, é a dificuldade em se encontrar um método adequado de dosagem, pois esta representa apenas um terço da vitamina B12 circulante e, além disso, a maior parte da transcobalamina circula insaturada com vitamina $B 12$, na forma de apo-transcobalamina ${ }^{(66,72)}$, e a holo-Tc, quando ligada à vitamina B12, precipita sob uma variedade de condições, entre as quais altas concentrações protéicas e baixos valores de $\mathrm{pH}^{(4)}$. $\mathrm{O}$ desenvolvimento de métodos imunológicos para a medida de Tc também tem sido dificultado pelo fato de esta proteína ser facilmente precipitada em solução $0^{(73)}$. Soma-se a isso o fato de apresentar um ciclo fisiológico complexo e passível de ser afetado por diversos mecanismos patológicos ainda não completamente compreendidos ${ }^{(20)}$. Em casos de insuficiência renal e/ou hepática, os níveis de holo-Tc circulante podem ser afetados e, nessas circunstâncias, não devem ser usados como marcadores dos níveis de vitamina B12 ${ }^{(42,63)}$.

Entre os trabalhos publicados para a dosagem de holoTc, freqüentemente a transcobalamina é separada de outra proteína ligante de vitamina $\mathrm{B} 12$, a haptocorrina $(\mathrm{Hc})$, antes de quantificar a vitamina B12. Isso permite uma medida direta da vitamina B12 ligada à holo-TC ${ }^{(74)}$ ou um cálculo indireto de holo-Tc através da dosagem de vitamina B12 sérica total subtraída da dosagem de vitamina B12 não ligada a holo- $\mathrm{TC}^{(8,101)}$, a qual se apresenta geralmente em maiores concentrações plasmáticas que a holo-Tc, favorecendo sua dosagem ${ }^{(66,72)}$. Uma das características fundamentais que minimizam a dificuldade de separação das duas proteínas transportadoras é que a holo-Tc é uma proteína não-glicada, ao passo que a holo-Hc é uma glicoproteína ${ }^{(11)}$.

A separação entre holo-Tc e holo-Hc é feita através de diferenças de adsorção dessas duas frações, usando-se adsorventes como sílica microfina ${ }^{(20,61)}$ (com capacidade de adsorver pequenas proteínas não-glicosiladas, como a holo-Tc II, sem adsorver glicoproteínas como a holo-Hc)(11), imunoadsorção ou cromatografia líquida, estes dois últimos mais inviáveis ${ }^{(20)}$. Alguns novos métodos para separar holoTc têm solucionado muitos dos problemas técnicos. Ambos utilizam um ensaio específico com anticorpos anti-Tc ${ }^{(74,99)}$. No trabalho de Ulleland et al. ${ }^{(99)}$, a transcobalamina sérica ou plasmática é capturada e concentrada por anticorpo monoclonal com alta afinidade imobilizada em microesferas magnéticas; a vitamina B12 ligada à Tc é então liberada e medida por um ensaio convencional para dosagem de vitamina $B 12^{(99)}$. Em outro trabalho, Nexo et al..$^{(74)}$ produziram partículas magnéticas ligadas com vitamina $\mathrm{B} 12 \mathrm{e}$ as utilizaram para remover a transcobalamina livre (apo-Tc) antes de uma quantificação de holo-Tc por enzyme linked immunosorbent assay (ELISA) ${ }^{(74)}$. Assim, eles evitaram a interferência de elevadas concentrações de apo-Tc na dosagem de holo-Tc detectada em estudo prévio(20).

Embora métodos mais modernos usando imunoensaios venham sendo testados para uso comercial, ainda não há aprovação para uso na rotina ${ }^{(19)}$. Além do mais, a utilidade clínica de holo-Tc ainda não foi validada completamente, e o conhecimento dos fatores que influenciam seus níveis ainda é limitado. Mesmo assim, sabe-se que holo-Tc pode ser um marcador mais específico e sensível no diagnóstico de deficiência de vitamina $B 12$ do que a própria determinação da vitamina B12 sérica(53), e os estudos continuam em busca de uma metodologia mais apropriada.

\section{MMA}

O desenvolvimento de ensaios específicos para MMA em urina, soro ou plasma tem viabilizado diagnosticar insuficiência de vitamina $B 12^{(68,91)}$ e ainda tem tornado 
possível diferenciá-la da deficiência de folatos, já que esta última condição não eleva o $\mathrm{MMA}^{(68)}$.

Elevações do MMA ocorrem precocemente nas deficiências de vitamina $B 12^{(91)}$ e representam alterações dos níveis intracelulares desse metabólito ${ }^{(40)}$. A deficiência de vitamina B12 ocorre quando níveis de MMA estão superiores a $0,4 \mu \mathrm{mol} / \mathrm{l}$ no soro ${ }^{(3)}$, ou maiores que $3,2 \mathrm{mmol} / \mathrm{mol}$ de creatinina na urina para adultos ${ }^{(65)}$ e superiores a 20$23 \mathrm{mmol} / \mathrm{mol}$ creatinina em crianças $^{(68)}$.

O MMA é um indicador mais sensível para diagnosticar uma deficiência de vitamina B12 intracelular do que dosagem de vitamina $B 12$ sérica ${ }^{(3,18,43,47,52)}$ e, entre os metabólitos, o MMA é freqüentemente considerado superior à Hcy

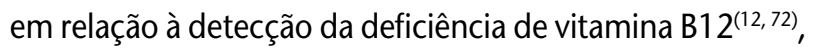
por ser mais específico e menos suscetível a erros préanalíticos ${ }^{(52)}$. Porém, não é um marcador completamente específico dos níveis de vitamina B12, porque a sua concentração se eleva na insuficiência renal( ${ }^{(43,76)}$, na gravidez ${ }^{(76)}$, nas doenças da tireóide, em condições de hemoconcentração e no aumento intestinal de bactérias produtoras de ácido propiônico, precursor do $\mathrm{MMA}^{(12,76)}$.

Além disso, há problemas analíticos que prejudicam seu uso na rotina laboratorial, como a necessidade de cromatografia gasosa associada à espectrometria de massa, que apresenta alto custo e necessidade de pessoal treinado, limitando sua utilização no diagnóstico laboratoria|(5, 19, 56, 104).

O MMA é bioquimicamente mais estável na urina do que no soro/plasma, e está 40 vezes mais concentrado ${ }^{(56)}$. Além do mais, a medida de MMA urinário é um método nãoinvasivo para utilização em pediatria ${ }^{(76)}$, triagens ou estudos epidemiológicos. Porém uma importante limitação desse índice é o fato de que a excreção urinária de MMA aumenta significativamente após a ingestão de alimentos ${ }^{(56)}$ e nas condições citadas para o MMA sérico, tendo sido reportados freqüentes problemas com resultados falso-positivos para este indicador na urina ${ }^{(76)}$. Dessa forma, o emprego de dosagens urinárias não é ainda recomendado ${ }^{(19)}$.

\section{Hcy}

A Hcy é um dos mais sensíveis indicadores de deficiência de vitamina B12, pois aparece precocemente no decorrer da deficiência, precedendo os sintomas clínicos ${ }^{(5,19,87)}$. Savage et al. ${ }^{\left({ }^{77}\right)}$ realizaram um estudo com 406 pacientes que estavam sendo investigados para anemia megaloblástica, quando constataram que $95,9 \%$ dos indivíduos apresentavam elevações de Hcy sérica( ${ }^{(87)}$.
Uma associação de MMA e Hcy poderia ser útil devido à possibilidade de diferenciação entre deficiência de vitamina B12 e deficiência de folatos. O MMA estará elevado apenas na insuficiência de vitamina B12, enquanto a Hcy se eleva na de vitamina B12 e também na de folatos ${ }^{(91)}$. Savage et al. ${ }^{(97)}$, usando 434 pacientes com deficiência de vitamina B12, constataram que $98,4 \%$ apresentaram elevações de MMA e 95,9\%, níveis de Hcy aumentados em até três vezes em comparação com os controles. A deficiência de folatos foi verificada em 123 indivíduos, e ,destes, 91\% apresentavam hiper-homocisteinemia e somente $12,2 \%$ aumento de MMA, que foi atribuído a insuficiência renal e hipovolemia ${ }^{(87)}$.

Além da deficiência de vitamina B12 e folatos, existem outras situações em que ocorre uma Hcy, como deficiência de vitamina $B 6$, insuficiência renal ${ }^{(18,47)}$, deficiência de cistationina sintase ${ }^{(67)}$ e nos erros inatos do metabolismo, contribuindo para a baixa especificidade do teste. Deve-se levar em consideração também que os intervalos de referência da Hcy para diagnosticar deficiência de vitamina B12 não são ainda universalmente concordantes ${ }^{(19,24)}$.

A Hcy pode ser dosada por métodos cromatográficos, incluindo cromatografia gasosa com espectrometria de massa, cromatografia de troca iônica, cromatografia líquida de alta eficiência com detecção por fluorescência ou eletroquímica e eletroforese capilar ou por métodos imunológicos, como enzima imunoensaio e imunoensaio por fluorescência polarizada. Os princípios de separação e detecção variam de forma notável entre os métodos ${ }^{(37)}$, o que torna difícil uma padronização, além do custo desses testes que impedem sua utilização na rotina laboratorial e da enorme variabilidade na manipulação das amostras necessárias para alguns desses métodos ${ }^{(30)}$.

\section{Conclusões}

A deficiência de vitamina B12 inibe a função da metionina sintase e da L-metilmalonil-coA mutase, gerando Hcy e comprometendo as reações de metilação que levarão ao desenvolvimento de patologias principalmente cérebro e cardiovasculares de diferentes graus de severidade, podendo até mesmo tornarem-se irreversíveis. Além disso, deficiências subclínicas da vitamina B12 podem contribuir silenciosamente para problemas cardíacos e neurológicos, desde os de ordem sensoriais até os distúrbios psiquiátricos e da aprendizagem.

Disfunções neurológicas isoladas podem ser o resultado clínico da deficiência crônica de vitamina B12 mesmo sem nenhum sinal de anemia ${ }^{(18)}$. 
Apesar da importância dos quadros associados a essa deficiência, o diagnóstico laboratorial ainda não é simples, embora novas metodologias e estratégias estejam surgindo nos últimos anos. Um diagnóstico correto e precoce de deficiência de vitamina B12, principalmente nos casos subclínicos, representa ainda um desafio. Muitos estudos para o diagnóstico da deficiência são realizados por diferentes metodologias, o que torna muito difícil estabelecer comparações apropriadas entre os diferentes estudos.

A utilização com cautela das dosagens de MMA e Hcy pode ser uma alternativa para o diagnóstico precoce da deficiência de vitamina B12. Outra possibilidade que futuramente poderá ser utilizada é a dosagem de holo-Tc, diferenciando-se a vitamina B12 realmente ativa e disponível da total. Porém, para isso, novas pesquisas metodológicas deverão ser desenvolvidas.

\section{Referências}

I.AFMAN, L.A. et al. Reduced vitamin B 2 binding by transcobalamin II increases the risk of neural tube defects. Q J Med, v. 94, n. 3, p. | 159-66, 2001.

2. ALLEN, L. H. et al. Vitamin B- 12 deficiency and malabsorption are highly prevalent in rural Mexican communities. Am J Clin Nutr, v. 62, n. 5, p. 1013-1019, 1995.

3.ALLEN, R. H. et al. Metabolic abnormalities in cobalamin (vitaminBI2) and folate deficiency. FASEB J, v. 7, n. 14, p. 1344-53, 1993.

4. ALLEN, R. H.; MAJERUS, P.W. Isolation of vitamin $B_{12}$-binding proteins using affinity chromatography. III. Purification and properties of human plasma transcobalamin II.J Biol Chem, v. 247, n. 23, p. 7709-17, 1972.

5. AMOS, R. J. et al. Guidelines on the investigations and diagnosis of cobalamin and folate deficiencies. Clin Lab Haematol, v. 16, n. 2, p. 101-15, 1994.

6. ANDRES, E. et al. Vitamin BI2 (cobalamin) deficiency in elderly patients. CMAJ, v. I7I, n. 3, p. 25I-9, 2004.

7. BABIDGE, P. J); BABIDGE,W. J. Determination of methylmalonic acid by high-performance liquid chromatography. Anal Biochem, v. 216, n. 2, p. 424-6, 1994.

8. BAKER, H. et al. Cobalamin (vitamin BI2) and holotranscobalamin changes in plasma and liver tissue in alcoholics with liver disease. J Am Coll Nutr, v. 17, n. 3, p. 235-8, 1998.

9. BANERJEE, R. V.; MATTHEWS, R. G. Cobalamin: dependent methionine synthase. FASEB, v. 4, n. 5, p. 1450-9, 1990.

10. BARRIOS, M. F. et al. Vitamina $B_{12}$ : metabolismo y aspectos clínicos de su deficiencia. Rev Cubana Hematol Inmunol Hemoter, v. 15, n. 3, p. 159-74, 1999.

I I. BENHAYOUN, S. et al. Method for the direct specific measurement of vitamin $B_{12}$ bound to transcobalamin II in plasma. Acta Haematol, v. 89, n. 4, p. 195-9, 1993.

12. BOLANN, B. J. et al. Evaluation of indicators of cobalamin deficiency defined as cobalamin-induced reduction in increased serum methylmalonic acid. Clin Chem, v. 46, n. II, p. 1744-50, 2000.

13. BOSS, G. R. Cobalamin inactivation decreases purine and methionine synthesis in cultured lymphoblasts. J Clin Invest, v. 76, n. I, p. 213-8, 1985.

14.BOSTON,A. G. et al. Nonfasting plasma total homocysteine levels and stroke incidence in elderly persons: the Framingham study. Annu Intern Med, v. I3I, n. 5, p. 352-5, 1999.
15. BOUSHEY, C. J. et al. A quantitative assessment of plasma homocysteine as a risk factor for vascular disease. Probable benefits of increasing folic acid intakes. JAMA, v. 274, n. 13 , p. 1049-57, 1995.

16. BROSNAN, J.T. et al. Methylation demand: a key determinant of homocysteine metabolism. Acta Biochim Pol, v. 5I, n. 2, p. 405- I 3, 2004.

17. CABEZAS, A. M.; RODRIGUES, J. E. F. B. Metabolismo de la homocisteína y su relación com la aterosclerosis. Rev Cubana Invest Bioméd, v. 18, n. 3, p. 155-68, 1999.

18. CARMEL, R. Current concepts in cobalamin deficiency. Annu Rev Med, v. 5I, p. 357-75, 2000.

19. CARMEL, R. et al. Update on cobalamin, folate, and homocysteine. Hematology (Am Soc Hematol Educ Program), p. 62-81, 2003.

20. CARMEL, R. Measuring and interpreting holo-transcobalamin (holo-transcobalamin II). Clin Chem, v. 48, n. 3, p. 407-9, 2002.

21. CARMEL, R. Mild transcobalamin I (haptocorrin) deficiency and low serum cobalamin concentrations. Clin Chem, v. 49, n. 8, p. I367-74, 2003.

22. CHANARIN, I.; METZ, J. Diagnosis of cobalamin deficiency: the old and the new. Br J Haematol, v. 97, n. 4, p. 695-700, 1997.

23. CHANDALIA, M. et al. Hyperhomocysteinemia in Asian indians living in the United States. J Clin Endocrinol Metab, v. 88, n. 3, p. 1089-95, 2003.

24. CLARKE, R. et al. Screening for vitamin B-12 and folate deficiency in older persons. Am J Clin Nutr, v. 77, n. 5, p. 1241-7, 2003.

25. COLE, D. E. C.; LANGMAN, L. J. Homocysteine: cholesterol of the 90s? Clin Chim Acta, v. 286, n. I-2, p. 63-80, 1999.

26. COOPER, B. A.; ROSENBLATT, D. S.; WHITEHEAD, V. M. Megaloblastic anemia. In: NATHAN, D. G.; OSKI, F. A. Hematology of infancy and childhood. 4. ed. Philadelphia:W. B. Saunders Company, I993. p. 698.

27. COPPEN, A.; BOLANDER-GOUAILLE, C. Treatment of depression: time to consider folic acid and vitamin BI2.J Psychopharmacol, v. 19, n. I, p. 59-65, 2005.

28. DESAI, A. et al. Homocysteine augments cytokine-induced chemokine expression in human vascular smooth muscle cells: implications for atherogenesis. Inflammation, v. 25, n. 3 , p. |79-86, 200।. 
29. DIEZ-EWALD, M. et al. Prevalence of anemia, iron, folic acid and vitamin $\mathrm{B} / 2$ deficiency in two Bari Indian communities from western Venezuela. Invest Clin, v. 38, n. 4, p. 191-20I, 1997.

30. DUCROS, V. et al. Review: methods for homocysteine analysis and biological relevance of the results.) Chromatogr B, v. 78I, n. I-2, p. 207-26, 2002.

3।.ENGLAND,J.M.; LINNELL,J. C. Problems with the serum vitamin $\mathrm{B}_{12}$ assay. The Lancet, v. 316, n. 8203, p. 1072-4, 1980.

32. FAIRBANKS, V. F.; KLEE, G. G. Aspectos bioquímicos da hematologia. In: BURTIS, C. A.; ASHWOOD, E. R. Tietz: fundamentos de química clínica. 4. ed. Rio de Janeiro: Guanabarra Koogan S. A., 1998. Cap. 36, p. 699-703.

33. FINKELSTEIN, J. D. Methionine metabolism in mammals.J Nutr Biochem, v. I, n. 5, p. 228-37, 1990.

34. FRANKEL, R. M.; MILLER, K. B.; CAPONE, R. C. Ocular, neurologic and hematologic manifestations of na inherited abnormality in vitamin $B_{12}$ metabolism: case study and review of the literature. Clin Eye Vis Care, v. 8, n. 3, p. I81-5, 1996.

35. GABRIEL, S. A. et al. Homocisteína como fator de risco para doenças cardiovasculares. Rev Fac Ciên Med Sorocaba,v. 7 , n. I, p. I I-4, 2005.

36. GALLUCCI, M. et al. Homocysteine in Alzheimer disease and vascular dementia. Arch Gerontol Geriatr Suppl, v. 9, p. $195-$ 200, 2004

37. GARCIA, A. J:; APITZ-CASTRO, R. Plasma total homocisteyne quantification: an improvement of the classical highperformance liquid chromatography method with fluorescence detection of the thiol-SBD derivatives. J Chromatogr B, v. 779, n. 2, p. 359-63, 2002.

38. GILLHAM, B.; PAPACHRISTODOULOU, D. K.; THOMAS, J. H. Wills': biochemical basis of medicine. 3. ed. Oxford: Reed Educational and Professional Publishing Ltd, 1997. Cap. 22, p. 196-202.

39. GRAHAM, S. M. et al. Long-term neurologic consequences of nutritional vitamin B 12 deficiency in infants.J Pediatr, v. 121 , n. 5, p. 710-4, 1992.

40. GÜLTEPE, M. et al. Urine methylmalonic acid measurements for the assessment of cobalamin deficiency related to neuropsychiatric disorders. Clin Biochem, v. 36, n. 4, p. $275-$ 82, 2003.

4I. HENRY, J. B. Diagnósticos clínicos e tratamento por métodos laboratoriais. 2. ed. São Paulo: Manole Ltda, 1999. Cap. 26, p. $621-5$.

42. HERRMANN, W. et al. Functional vitamin BI2 deficiency and determination of holotranscobalamin in populations at risk. Clin Chem Lab Med, v. 4I, n. I I, p. I478-88, 2003.

43. HERRMANN,W. et al. Role of homocysteine, cystathionine and methylmalonic acid measurement for diagnosis of vitamin deficiency in high-aged subjects. Eur J Clin Invest, v. 30, n. 12 , p. 1083-9, 2000.

44. HERRMANN, W. et al. The usefulness of holotranscobalamin in predicting vitamin $\mathrm{B} 12$ status in different clinical settings. Curr Drug Metab, v. 6, n. I, p. 47-53, 2005.

45. HERRMANN, W. et al. Total homocysteine, vitamin B(I2) and total antioxidant status in vegetarians. Clin Chem, v. 47, n. 6, p. |094-101,200।.
46. HERRMANN, W. et al. Vitamin B-12 status, particularly holotranscobalamin II and methylmalonic acid concentrations, and hyperhomocysteinemia in vegetarians. Am J Clin Nutr, v. 78, n. I, p. I31-6, 2003.

47. HERRMANN,W.; GEISEL, J.Vegetarian lifestyle and monitoring of vitamin B-12 status. Clin Chim Acta, v. 326, n. I-2, p. 47$59,2002$.

48. HINTIKKA, J. et al. High vitamin $\mathrm{B}_{12}$ level and good treatment outcome may be associated in major depressive disorder. BMC Psychiatry, v. 3, n. I, p. 17, 2003.

49. HOFFBRAND, A.V.; JACKSON, B. F. A. Correction of the DNA synthesis defect in vitamin $B_{12}$ deficiency by tetrahydrofolate: evidence in favour of the methyl-folate trap hypothesis as the cause of megaloblastic anaemia in vitamin $\mathrm{B}_{12}$ deficiency. BrJ Haematol, v. 83, n. 4, p. 643-7, 1993.

50. HOFFER, L.J. Homocysteine remethylation and trans-sulfuration. Metabolism, v. 53, n. II, p. 1480-3, 2004.

5I. HOFMANN, M. A. et al. Hyperhomocysteinemia enhances vascular inflammation and accelerates atherosclerosis in a murine model. J Clin Invest, v. 107, n. 6, p. 675-83, 2001.

52. HOLLELAND, G. et al. Cobalamin deficiency in general practice. Assessment of the diagnostic utility and costbenefit analysis of methylmalonic acid determination in relation to current diagnostic strategies. Clin Chem, v. 45, n. 2. p. 189-98, 1999.

53. HVAS, A. M.; NEXO, E. Holotranscobalamin: a first choice assay for diagnosing early vitamin $B_{12}$ deficiency? I Intern Med, v. 257, n. 3, p. 289-98, 2005.

54. KIRKE, P. N. et al. Maternal plasma folate and vitamin BI2 are independent risk factors for neural tube defects. Q J Med, v. 86, n. II, p. 703-8, 1993.

55. KLEE, G. G. Cobalamin and folate evaluation: measurement of methylmalonic acid and homocysteine vs vitamin B(I2) and folate. Clin Chem, v. 46, n. 8 (pt2), p. 1277-83, 2000.

56. KWOK, M. D. et al. Use of fasting urinary methylmalonic acid to screen for metabolic vitamin B 12 deficiency in older persons. Nutrition, v. 20, n. 9, p. 764-8, 2004.

57. LEE, D. S.; GRIFFITHS, B. W. Human serum vitamin BI2 assay methods: a review. Clin Biochem, v. I8, n. 5, p. 26।-6, 1985.

58. LEE, G. R. (Org.). Wintrobe: Hematologia clínica. v. I. São Paulo: Manole Ltda, 1998. Cap. 24, p. 8I8-54.

59. LEE, M.;WANG, H. Homocysteine and hypomethylation: a novel link to vascular disease. Trends Cardiovasc Med, v. 9, n. I-2, p. 49-54, 1999.

60. LINDENBAUM, J. et al. Diagnosis of cobalamin deficiency: II. Relative sensitivities of serum cobalamin, methylmalonic acid, and total homocysteine concentrations. Am J Hematol, v. 34, n. 2, p. 99-107, 1990.

6I. LINDGREN, A. et al. Holotranscobalamin: a sensitive marker of cobalamin malabsorption. Eur J lin Invest, v. 29, n. 4, p. $321-9,1999$.

62. LLOYD-WRIGHT, Z. et al. Holotranscobalamin as an indicator of dietary vitamin $B_{12}$ deficiency. Clin Chem, v. 49, n. 12, p. 2076-8, 2003.

63. LOIKAS, S. et al. RIA for serum holo-transcobalamin: method 
evaluation in the clinical laboratory and reference interval. Clin Chem, v. 49, n. 3, p. 455-62, 2003.

64. LORENZI, T. F. Manual de hematologia: propedêutica e clínica. Rio de Janeiro: MEDSI, 1992.

65. MARCELL, P. D. et al. Quantitation of methylmalonic acid and other dicarboxilic acids in normal serum and urine using capillary gas chromatography-mass spectrometry. Anal Biochem, v. I50, n. I, p. 58-66, 1985.

66. MARKLE, H.V. Cobalamin. Crit Ver Cli Lab Sci, v. 33, n. 4, p. 247356, 1996.

67. McCULLY, K. S. Homocysteine, vitamin deficiency and prevention of arteriosclerosis. Integr Med, v. I, n. I, p. 3-9, 1998.

68. MONSEN, A. L. B.; UELAND, M. P. Homocysteine and methylmalonic acid in diagnosis and risk assessment from infancy to adolescence. Am J Clin Nutr, v. 78, n. I, p. 7-21, 2003.

69. MORETTI, R. et al. Vitamin BI2 and folate depletion in cognition: a review. Neurol India, v. 52, n. 3, p. 310-8, 2004.

70. MORRIS, M. S. et al. Elevated serum methylmalonic acid concentrations are common among elderly americans. J Nutr, v. I 32, n. 9, p. 2799-803, 2002.

7I. NEVES, L. B. et al. Homocisteína.J Bras Patol Med Lab, v. 40, n. 5, p. 31|-20, 200।

72. NEXO, E. et al. How to diagnose cobalamin deficiency. Scand J Clin Lab Invest, v. 54, suppl. 219, p. 61-76, 1994.

73. NEXO, E. et al. Measurement of transcobalamin by ELISA. Clin Chem, v. 46, n. I0, p. 1643-9, 2000.

74. NEXO, E. et al. Quantification of holo-transcobalamin, a marker of vitamin $B_{12}$ deficiency. Clin Chem, v. 48, n. 3, p. $561-2,2002$.

75. NILSSON, K. et al. Lack of association between plasma homocysteine and inflammation in psychogeriatric patients. Dement Geriatr Cogn Disord, v. I4, p. I 5 - -5, 2002.

76. NORMAN, E. J. Urinary methylmalonic acid/creatinine ratio defines true tissue cobalamin deficiency. Br J Haematol, v. 100, n. 3, p. 614-5, author reply 617-8, 1998.

77. OBEID, R. et al. Cellular uptake of vitamin $B_{12}$ in patients with chronic renal failure. Nephron Clin Pract, v. 99, n. 2, p. 42-8, 2005.

78. OBEID, R. et al. Cobalamin status (holo-transcabalamin, methylmalonic acid) and folate as determinants of homocysteine concentration. Clin Chem, v. 48, n. II, p. 2064-5, 2002.

79. OBEID, R. et al. Vitamin BI2 status in the elderly as judged by available biochemical markers. Clin Chem, v. 50, n. I, p. 238-4I, 2004.

80. OKUDA, K. Discovery of vitamin $B_{12}$ in the liver and its absorption factor in the stomach: a historical review. J Gastroenterol Hepatol, v. I4, n. 4, p. 301-8, 1999.

8I. O'SULLIVAN,J..J. et al. Radioimmunoassay that measures serum vitamin BI2.J Clin Pathol, v. 45, n. 4, p. 328-31, 1992.

82. PENNINX, B.W. et al. Vitamin B(I2) deficiency and depression in physically disabled older women: epidemiologic evidence from the women's health and aging study. Am J Psychiatry, v. I57, n. 5, p. 7|5-2|, 2000.

83. PODDAR, R. et al. Homocysteine induces expression and secretion of monocyte chemoattractant protein-I and interleukin-8 in human aortic endothelial cells: implications for vascular disease. Circulation, v. 103, n. 22, p. 2717-23, 200 I.

84. QUADROS, E.V. et al. Purification and molecular characterization of human transcobalamin II. J Biol Chem, v. 26I, n. 33, p. 15455-60, 1986.

85. REFSUN, H. et al. Hyperhomocysteinemia and elevated methylmalonic acid indicate a high prevalence of cobalamin deficiency in Asian Indians. Am J Clin Nutr, v. 74, n. 2, p. 2334I, 200I.

86. ROTHENBERG, S. P.; QUADROS, E. V. Quantitative methods for measurement of transcobalamin II. Methods Enzymol, v. 28I, p. 26I-8, 1997.

87. SAVAGE, D. G. et al. Sensitivity of serum methylmalonic acid and total homocysteine determinations for diagnosing cobalamin and folate deficiences. Am J Med, v. 96, n. 3, p. 239-46, 1994

88. SAVAGE, D.G.; LINDENBAUM, J. Neurological complications of acquired cobalamin deficiency: clinical aspects. Baillieres Clin Haematol, v. 8, n. 3, p. 657-78, 1995.

89.SCANDURRA, R;:POLITI, L. Methods of determination of vitamin B 12. Acta Vitaminol Enzymol, v. 3, n. 4, p. 205-13, 198 I.

90. SILVA, P. Farmacologia. 6. ed. Rio de Janeiro: Guanabara Koogan, 2002.

91. SNOW, C. F. Laboratory diagnosis of vitamin $B_{12}$ and folate deficiency: a guide for the primary care physician. Arch Intern Med, v. 159, n. 12, p. 1289-98, 1999

92. SPLAVER, A. et al. Homocysteine and cardiovascular disease: biological mechanisms, observational epidemiology, and the need for randomized trials. Am Heart J, v. 148, n. I, p. 34-40, 2004.

93. STABLER, S. P.et al. Clinical spectrum and diagnosis of cobalamin deficiency. Blood, v. 76, n. 5, p. 87I-8I, 1990.

94. STEIJNS, L. S.W. et al. Evaluation of nonisotopic binding assays for measuring vitamin $B_{12}$ and folate in serum. Clin Chim Acta, v. 248, n. 2, p. 135-41, 1996.

95. STROINSKY, A.; SCHNEIDER, Z. Cobamide dependant enzymes. In: SCHNEIDER, Z; STROINSKY, A., editors. Comprehensive B-12. Berlin: Printing House de Gruyter, 1987. p. 225-66.

96. TIEMEIR, $H$. et al. Vitamin $B_{12}$, folate and homocysteine in depression: the Rotterdam Study. Am J Psychiatry, v. I59, n. 12, p. 2099-101, 2002.

97. TISMAN, G. et al. Measurement of red cell-vitamin BI2: a study of the correlation between intracellular B 2 content and concentrations of plasma holotranscobalamin II. Am J Hematol, v. 43, n. 3, p. 226-9, 1993.

98.TRIPATHI, M. et al. Serum cobalamin levels in dementias. Neurol India, v. 49, n. 3, p. 284-6, 2001.

99. ULLELAND, M. et al. Direct assay for cobalamin bound to transcobalamin (holo-transcobalamin) in serum. Clin Chem, V. 48, n. 3, p. 526-32, 2002.

100. VENÂNCIO, L. S.; BURINI, R. C.; YOSHIDA, W. B. Hiperhomocisteinemia na doença arterial periférica. J Vasc $B r$, v. 3, n. I, p. 3I-7, 2004.

I0 I.VU,T. et al. New assay for the rapid determination of plasma holotranscobalamin II levels: preliminary evaluation in cancer patients. Am J Hematol, v. 42, n. 2, p. 202-1 I, 1993. 
102. WEISS, N. Mechanisms of increased vascular oxidant stress in hyperhomocysteinemia and its impact on endothelial function. Curr Drug Metab, v. 6, n. I, p. 27-36, 2005.

103. WELCH, G. N.; LOSCALZO, J. Homocysteine and atherothrombosis. N Engl J Med, v. 338, n. I5, p. 1042-50, 1998.

104. YAZDANPANAH, M. et al. An improved assay for plasma methylmalonic acid using chemical ionization gas chromatography mass spectrometry. Clin Biochem, v. 36, n. 8, p. 17-620, 2003.

105. ZAGO, M. A.; MALVEZZI, M. Deficiência de vitamina BI2 e de folatos: anemias megaloblásticas. In: FALCÃO, R. P.; PASQUINI, R. Hematologia: fundamentos e prática. São Paulo: Atheneu, 2001. Cap. 21, p. 195-210. 